\title{
LA HISTORIA DE AYER VISTA POR LOS INDÍGENAS DE HOY
}

\author{
Por \\ Everardo Garduño*
}

\begin{abstract}
RESUMEN
Este artículo no tiene mayores intenciones que las de explorar las posibilidades de emplear la historia oral como herramienta para interpretar el presente de las comunidades indígenas. Partiendo de la premisa de los historiadores que condenan a la imposibilidad de hacer historia o antropología del pasado por medio de la voz viva, aquí se pretende revelar que tal vez sea posible encontrar una nueva óptica del presente, observando el pasado, o escuchando lo que aún se recuerde de él.

De esta manera, el estigma de la subjetividad, de la ideologización de la historia, del sesgo en la información histórica, etcétera, aspira a abandonar el recinto de las fatalidades en el que han sido alojados por los historiadores, y llama a las puertas de donde se albergan los instrumentos metodológicos más reconocidos.

Esta perspectiva es la que orienta el presente artículo en el que se revisan los lugares comunes en los que incurren las distintas versiones que el investigador recogió entre 15 informantes de las comunidades indígenas montañesas de Baja California, acerca de su proceso de colonización, encontrando aspectos realmente interesantes.
\end{abstract}

\begin{abstract}
This is an article written with the intention to explore the possibilities of employing oral history as a tool to interprete the present of the aboriginal comunities. Parting from the premise of the historians who condemn the posibility of gathering information on the history or anthropology of the past through the voices of those who live, this article pretends to reveal that perhaps it is possible to find a new optic of the present, observing the past, or listening to what is still remembered of it.

In this way the estigma of subjectivity, of ideologizing history, of the slant in historical information, aspires to leave the place of fatalities in which it has been lodged by some historians, and calls to the doors of a place where the most renowned methodological instruments are kept.

This perspective is the one that orients the present article in which we review the common points of different versions about the process of colonization, that the author collected among 15 informants of the mountain indians of Baja California.
\end{abstract}

\section{INTRODUCCIÓN}

* Investigador de Instituto de Investigaciones Históricas de la UABC. 


\section{INTRODUCCIÓN}

Sin lugar a dudas, tal y como lo advierte Homer Aschmann (1965), es importante retomar el estudio de los indígenas de Baja California a través de los documentos misionales, ya que como lo afirma el mismo autor, aun cuando los primeros estudios antropologicos sobre estas etnias se llevaron a cabo en los albores del presente siglo, no pueden ofrecernos información confiable acerca de lo que fueron estas culturas aborígenes hace cuatrocientos años, debido a que estos grupos, de acuerdo con la afirmación de Mauricio Mixco (1983), son en la actualidad básicamente culturas que viven a través de la memoria y no de su existencia física.

Esta dificultad se agrava aún más si tomamos en cuenta que la memoria colectiva indígena ha sido diseñada a lo largo de todo el proceso de colonización y que por lo tanto reproduce los valores, la ideología, los estereotipos y los puntos de vista del colonizador acerca del mismo proceso histórico; de tal forma que si no es posible hacer antropología de la cultura original de los grupos aborígenes de la península a través del testimonio de sus sobrevivientes, resulta mucho más arriesgado hacer historia apoyándose en sus recuerdos transmitidos de boca en boca, a lo largo de los siglos.

Sin embargo, quiero con este artículo iniciar un recorrido no menos riesgoso que el anterior, quiero seguir las difusas huellas de la historia a través de las versiones que los indígenas sostienen en el presente acerca de su historia, y por qué no, tratar de vislumbrar cómo perciben el hoy de sus comunidades, a través de su memoria del ayer; esto es, empezar a hacer antropología de su presente, apoyado en su visión inexacta de la historia.

Después de todo, si los historiadores ofrecen culto al documento escrito y desdeñan la palabra, apoyándose en una historiografía del periodo misional, documentada y escrita por los propios misioneros que ya han muerto, por qué no hacer culto a la historia oral, no documentada e imprecisa, pero de los indígenas que aún viven.

Cierto que la primer visión conserva y refleja la óptica y las exageraciones de los europeos mientras que la segunda se presenta con vacíos de información y abusos en la subjetividad por parte de los aborígenes; cierto que ninguno de estos últimos vivió los hechos que relata y sólo los escuchó de algún anciano, de algún antropólogo que lo visitó, o bien lo leyó de un libro que llegó a sus manos. Pero a pesar de esto, la segunda visión actúa como un espejo a través del cual el colonizador ve reflejadas las propias versiones, valores y estereotipos que ha generado en tomo a la historia y que ha impuesto en la memoria histórica de los indios, quienes a su vez han hecho una selección ideológica de estos elementos, los han mezclado con versiones originales provistas por su tradición oral y finalmente han 
diseñado su propia versión que nos expresa no sólo la imagen que conservan del colonizador en la historia, sino el concepto que tienen del colonizador en la actualidad. Porque creo que más allá de la inexactitud histórica en la versión actual indígena acerca del proceso de colonización, se encuentra un factor ideológico que nos habla de cómo los nativos de Baja California ven la historia relatada por sus abuelos o aprendida de los antropólogos y de los propios libros, y de cómo visten esta información con una determinada emotividad que es resultado de la interacción que todos los días viven con el mestizo y las dependencias gubernamentales, figuras a las que identifican como categorías históricas completamente ajenas a su ser y a su cultura.

Por ello, al conversar con nuestros informantes, constantemente nos hemos preguntado, ¿Hasta qué punto su propia visión de los hechos históricos rebela los estigmas de su encuentro cotidiano y actual con los colonizadores?

Seguramente esta pregunta no será contestada en el presente artículo, ya que nuestra intención es ofrecer al lector una revisión de la información de campo obtenida acerca de este tema, a través de sesiones con más de quince informantes pertenecientes a todas las comunidades indígenas del norte de Baja California. Toda esta información fue sintetizada y organizada temáticamente a partir de los momentos históricos que los propios entrevistados definieron a lo largo de su conversación, y que en términos generales son la época misional, la intervención magonista y el advenimiento de la colonización del siglo xx; posteriormente, analizamos todas las versiones disponibles con el objeto de encontrar aquellos lugares comunes en los que incurrieron la mayoría de los informantes; y por último, exponemos el presente artículo a través de las versiones que nos parecieron más claras, y que son las de Doña Teodora Cuero, indígena cochimí de La Huerta, Doña Ernestina Albañez, indígena kumiai residente de la comunidad cochimí de La Huerta, Doña Gloria Castañeda, indígena kumiai de San José de la Zorra, Don Benito Peralta, Don Gertrudis Ochurte y Don Carlos Cañedo, todos ellos indígenas paipai de la comunidad de Santa Catarina, y de Don Trinidad Ochurte, kiliwa del Arroyo de León.

Cabe señalar que el presente ensayo es sólo una breve reflexión de uno de los capítulos de un trabajo ${ }^{1}$ más amplio que está por ser publicado acerca de "La situación socioeconómica y el proceso de aculturación de los indígenas montañeses de Baja California".

1 Proyecto que fue financiado por el Consejo Nacional para la Cultura y las Artes y el Consejo Nacional de Ciencia y Tecnología. 
Los actuales indígenas del norte de Baja California advierten la existencia de por lo menos tres etapas en el proceso de colonizacion, y aun, algunos de ellos perciben cuatro: 1) la llegada de los frailes (los misioneros dominicos); 2) la guerra con los revoltosos (los magonistas); y 3) la invasión de los mineros, ganaderos y agricultores; etapa que dividen claramente entre: a) la llegada de los americanos, y b) la llegada de los mexicanos. Acerca de la primer etapa del contacto, los indígenas no establecen diferencia alguna entre los distintos tipos de colonizadores, para ellos todos son los frailes, cuya orden religiosa desconocen o confunden, e incluso, la figura del español es escasamente reconocida:

No, no recuerdo que por aquí hayan llegado los españoles a estos lugares, los únicos que llegaron fueron los frailes, pero los españoles, esos que descubrieron aquí, ¿América?, no, no sé. Tal vez en la capital sí. Los únicos que estuvieron por aquí fueron esos, los franciscanos, los frailes, los misionarios o misioneros, no sé (Benito Peralta).

Partiendo de esa homogenización general de los colonizadores en el primer contacto, tampoco establecen una diferencia entre las distintas razones que pudieron haber estimulado la colonización; para todos los indígenas el fraile era atraído a Baja California por razones de ambición, ya sea que buscara tierras e incluso oro:

Venían buscando tierra yo creo porque al ver aquí, hicieron eso [se refiere a un represo]. Ellos fueron los que empezaron a trabajar aquí, no nosotros. Porque ellos quien sabe qué andarían haciendo, andarían lavando oro, lavando otra cosa, pero hicieron trabajar aquí a la gente (Carlos Cañedo).

Querían todas las riquezas, oro; todo se llevaron; dicen que trajeron minas por aquí en los cerros, que están escondidas (Gertrudis Uchurte).

Los frailes se querían adueñar del lugar y de la gente, por eso venían poniendo iglesias en todas partes. Y si se fueron, es porque los indios les incendiaron las misiones (Benito Peralta).

Esta misma idea del fraile gambusino dio lugar a historias fantasiosas entre las comunidades.

Un tío mio que se murió de ciento y feria de años, decía que estaba viviendo más para acá de donde está el chorrito, más para acá de Catarina, allí para abajito donde se llama Cerro Colorado, dice que él estaba chiquito, estaría como el muchacho que anda aquí, y dice que oía pues las campanas de la mañana, de las 7 de la mañana, y las de 
las 5 de la tarde del rosario; pero esas campanas sonaban muy recio y se oían bien claritas, cerquitas dice que parecía que las sonaban, y ya ve que está lejos Santa Catarina de ahí, ¿verdad? Y es que eran de oro las campanas, no eran de cualquier material (Teodora Cuero, indígena tipai de La Huerta; información personal).

Los actuales indígenas reconocen además, que con la llegada de los frailes tuvo origen el sedentarismo y la implantación de un nuevo esquema de asentamiento, así como la introducción de nuevas pautas culturales, entre las que destacan siempre el trabajo:

Mis abuelos me platicaban todo eso, lo de la iglesia aquí donde estamos todavía la gente, los indios; pero como no sabíamos hablar nada de español nos juntaban y nos enseñaban a rezar, eso nos enseñaban (Benito Peralta).

Los frailes son los que arrimaron esto [la comunidad de Santa Catarina], vinieron a bacer iglesias ahí y la gente estaba por acá. Habría alguno por aquí y ese fue el que los juntó a todos los que andaban lejos.

Ajá, por orden de los frailes los juntaron, y los hicieron trabajar (Carlos Cañedo).

Invariablemente, el aspecto que los nativos destacan con mayor énfasis acerca de la presencia de los frailes, es el maltrato:

Pero también los maltrataban, mucho los maltrataban, mucho.

Les daban cualquier comida, cualquier cosa.

Los frailes, según mi tío y mi nana, maltrataban a los indígenas y los hacían trabajar sin sueldo; los hacían trabajar sin descanso y les daban sus chirrionasos. Los trataban como a un animal en los tiros, y muchas veces, también como los animales, los indios no jalaban ya de lo cansado o de lo golpeado; porque aquí se hicieron ladrillos, se hizo una asequia allá en unas tierras que están acá abajo, y que son como unos 3 ó 4 km de puro ladrillo; en eso hacían trabajar a los indios.

Los frailes pusieron la misión arriba a un lado del panteón, arriba del cerro (Benito Peralta).

No; yo sé que estuvieron los frailes por aquí, pero no sé como estuvo. Lo único que sé es que vinieron a matar a toda la gente, a los kiliwas, a los pai pai, a todos; querían ponerles fierros, señales, eso yo supe, me lo contó mi papá. Usaban espadas y todas esas cosas, por eso vinieron a matar gente (Trinidad Uchurte, indígena kiliwa de Arroyo de León; información personal). 
Los frailes hacían trabajar nomas dioquis, pues a pura, a pura joda, puro trabajo pesado, los maltrataban mucho, los hacían mucho trabajar en todo y como a los animales (Gertrudis Uchurte).

Para algunos como Ernestina Albañez, además del hostigamiento físico a los indígenas, los frailes, practicaban el hostigamiento sexual.

Sí como no, oía yo pláticas, ya vez que uno todo el tiempo anda asomándose donde no lo llaman [-risas-]. Sí, es cierto, oye uno plática y no falta a ver qué oye.

Pos' de los frailes dicen que andaban de misioneros, que bautizaban, que casaban. Pos' muchas cosas que hacían pero no sé a que más se dedicaban.

Yo oía, no me contaban, que muchos frailes no andaban en buenos pasos; que andaban detrás de las chamacas; que se robaban las chamacas; que las tenían escondidas en el monte, debajo de las piedras por ahí, y que cuando se iban, las dejaban otra vez de donde las habían levantado. Eso es lo que yo oía que decían: Hija, ya no dilatan en llegar los frailes; ya es tiempo que vengan. ¡Aguzadas!. Entonces dijo un día mi abuelita: "Sabes qué, vamos a hacer un túnel con una puerta bien cerrada, para encerrar todo lo que a los frailes les gusta, porque ésos, no vienen a otra cosa. Son curitas por encima, pero por dentro no están nada de curitas", dijo mi abuelita. "Ya ven, a mí me levantaron el vestido. Dicen que son santos, pero no son santos. No hay que tenerles confianza". Eso es lo que oía que platicaba la gente; que no eran buenos, que no eran de confianza (Ernestina Albañez, indígena kumiai residente de la comunidad cochimí de La Huerta; información personal).

Los indígenas en general identifican el fin del periodo misional como resultado de las rebeliones indígenas, las cuales tuvieron lugar como respuesta a los excesos de los frailes; en el caso de Benito Peralta y Gertrudis Uchurte, las rebeliones se dieron en el marco de la guerra encabezada por Don Miguel Hidalgo:

¿La misión?, la quemaron unos guerreros que me parece vinieron de por acá, pero la fecha no le puedo decir, mi nanita me contó, pero estaba chamacona todavía me parece; sí, mi nanita me contó que un día, como entre 8 y 9 de la noche se escaparon los indígenas y huyeron al cerro que queda hacia allá [el noreste], y cuando casi llegaban a él, mi nanita volteó hacia la misión y vio como empezó a arder, ya era de noche cuando iban subiendo ese cerro, iban como a la mitad, ya obscuro, ¿no?, y volteaban para atrás y divisaban la llamarada; algunos indígenas de los que se estaban escapando la habían prendido. 
Pero eso fue hace bastante tiempo, yo digo que ha de haber sido en tiempos de Hidalgo y Costillas; cuando ganó el pleito seguramente, y vinieron para acá a quemar la misión; digo yo eso, quien sabe (Benito Peralta).

En las últimas fue cuando sé que los indios pelearon, a palazos sí, como pudieron se defendieron, con arcos y con palos y con todo. Yo creo pues que fue por eso, por lo mismo, porque los frailes no hacían las cosas bien, ya era un desorden.

El Señor Hidalgo creo era el jefe que juntó a la gente, a la indiada, y corrieron a los españoles de aquí. Y aquí dejaron libre [...] (Gertrudis Uchurte).

En otros testimonios, se mantiene la idea de que algún indígena local fue el líder de las rebeliones:

La misión la quemaron porque los frailes, los franceses, ¿qué eran?, bueno, ellos se iban muy arriba, querían herrarlos, señalarlos, obligar a la indiada y eso no les gustaba.

A mí me lo contaron todo los mismos indios.

Yo creo que el [que] quemó la iglesia fue uno de aquí mismo, porque se juntaron, después de que no los trataban bien, se juntaron, unos de aquí y otros de por allá de la huerta, y les dijeron que los iban a matar a los frailes y se les vinieron encima, y no los agarraron (Carlos Cañedo; indígena paipai de Santa Catarina; información personal).

También sé que en esa época hubo guerra, que se mató mucha gente aquí en Guadalupe, es todo lo que sé.

Aquí el líder que andaba era mi bisabuelo, o mi tatarabuelo, era Jatñil (Gloria Castañeda, indígena kamiai de San José de la Zorra, información personal).

En el balance que establecen los indígenas sobre el periodo misional, valorizan como positiva la religión, el idioma español, el trabajo, la agricultura y la ganadería; mientras que Benito Peralta, estableciendo una fina diferencia entre religión y superstición, valoriza como positiva la primera y como negativa la segunda:

Sus enseñanzas para los indios fueron el rezo y el bautizo; ¿quién sabe si también enseñaban a leer y a escribir?, porque mis abuelos no sabían ni leer ni escribir.

Yo creo que de lo bueno que los frailes nos dejaron fue el rezo, la letra no, porque mis abuelos no sabían eso; también el trabajo, la agricultura y la ganadería. $\mathrm{Y}$ de lo malo que nos dejaron fueron las minas de oro, porque con ellas inculcaron entre los indios el miedo a la muerte. Porque cuando alguna persona no indígena descubría una mina con 
gallitos (piedras impregnadas de oro), contrataba a un indígena para trabajarla y le decía, que si alguna otra persona entraba a allí, moriría; esto sólo para que no le robaran. Desde entonces esa creencia existe entre los indios, hasta ahora (Benito Peralta, indígena paipai de Santa Catarina; información personal).

Lo que yo tengo entendido de cuando llegaron los españoles es que la gente aprendió a ponerse ropa, aprendieron también el español y la religión, porque antes la gente no sabía, no sabía nada de eso (Gloria Castañeda).

Finalmente es común encontrar la opinión de que los frailes no dejaron ninguna enseñanza positiva, sólo objetos históricos de valor con los que comerciaron posteriormente.

Pues, yo creo que no nos dejaron ninguna enseñanza, tal vez sí, pero yo creo que no, yo creo que nada. Los indios no hubieran echo eso, no hubieran peleado contra ellos si trajeran buenas enseñanzas.

Lo único que dejaron ya lo sacaron todo, pues dicen que dejaron muchas cosas, muchas cosas. Se lo llevaron todo al otro lado. Lo único que no se llevaron fueron las campanas, pero eso también las vendieron los mismos indios yo creo.

Había otra campana más chica, pero también esa la vendieron. Yo digo que la vendieron, pero eso fue ahora después, yo creo.

Había también unas joyas grandes que dejaron los frailes, yo digo también que las vendieron, porque según dicen, estaban unas por ahí pero yo no las conocí.

También quedaron unas cosas grandes, sí pues, de fierro; yo creo que ahí redetían algo y quien tenía esas cosas estaban por aquí, yo creo por ahí las tenían pero ya no, ya no hay ni uno; sí, los han de ver vendido, fierro macizo.

Después de los españoles, ya puros indios quedaron (Gertrudis Uchurte, indígena paipai de Santa Catarina; información personal).

El segundo evento histórico, o segunda fase en el proceso de colonización identificada por los indígenas, es el del periodo magonista, conocido entre ellos como la época de "los revoltosos".

Algunos, como Don Benito Peralta, tienen claro incluso, cual fue la ruta seguida por los revolucionarios para llegar a la zona habitada por ellos:

Luego llegaron los revoltosos, y sucedieron muchas cosas que me contó Pedro Castro[...] llegaron a San Miguel atravesando el desierto, venían de El Mayor a Agua Caliente (Benito Peralta). 
La presencia de los magonistas, al igual que la de los misioneros, lejos de estar asociada a algún tipo de filosofía o proposito racional, es concebida generalmente como negativa, pues se relaciona con la destruccion, la guerra, los asesinatos:

\begin{abstract}
¿Al papá de mi papá? ah, no. No, a él lo mataron, y a un hermano de él también lo mataron entre cinco o seis, allá por el lado de Catarina. Allí vivían ellos dos. El lugar todavía allí está, le dicen Jamao (Trini Uchurte).
\end{abstract}

El contexto histórico en el que se dieron los acontecimientos es desconocido o confundido con otras etapas históricas; cabe destacar lo sugerente que resulta la asociación que establece Ernestina Albañez entre los magonistas, la acordada y los judiciales:

Porque antes había muchas cosas de armas, pero quien sabe de qué año serían. Serían cuando eso que dicen de la cordada, porque en ese tiempo pasaron mucho por ahí. Mataban sin consideración a quien dijeran que les caiba mal, a ese lo tronaban; lo traían y le decían vete y por la espalda los mataban. Esos de la cordada son como ahora los judiciales. Andaban a caballo (Ernestina Albañez).

Solo en algunos casos, los indígenas, como Benito Peralta, identifican con relativa exactitud dicho contex to histórico:

Todo esto fue cuando Madero estaba agarrado con Porfirio creo, y cuando quiso quitarle la silla (Benito Peralta).

Nadie, excepto este mismo indígena, conoce con detalle lo que ocurrio en Santa Catarina, cuando Jorge González, su tío, resultó muerto:

Sabiendo que iban a llegar los magonistas, Pedro Castro, que trabajaba para la vigilancia de San Miguel, fue a recorrer el área rumbo al desierto; se dio cuenta que faltaba una persona en su casa; no hizo caso y se vino a comunicar con su jefe, que le decían "el cachora"; todo está sin novedad, le dijo; pero en cuanto se retiró de donde dio su parte, oyó ladridos de perro, volteó y vio un gentío que rodeaba la casa de mi tío, Jorge González; el cachora arrancó echando tiros junto con Pedro Castro y se pudieron dar cuenta que adentro estaba mi mamá, hermana mayor de Jorge González, y se dieron cuenta que tenían a dos hijos pequeños, hermanos míos; vieron también cómo le tiraron la casa a balazos a mi tío y cómo lo hirieron; al sentirse herido su tío les pidió a sus familiares que huyeran y que lo dejaran solo; su hermana junto con los dos niños lograron huir. Luego mi tío se asomó por su ventana y vio a un hombre con un caballo blanco que pasaba cerca de su vista; entonces mi tío aprovechó y disparó; hirió al 
hombre en una pierna a la altura de la rodilla; al caballo también lo hirió y lo mató; el hombre murió más tarde cuando llegó al Álamo; se llamaba Simón Berthold.

Alguna gente huyó a la montaña que está en el estẹ y otros se desparramaron hacia otras partes. Un mes pasaron arriba de ese cerro que se llama Pak'jot [cerro de Dios]; entre esa gente estaba mi mamá. Después bajaron a San Vicente donde se encontraron con parientes míos.

Los revoltosos estuvieron en El Álamo, el valle [de la Trinidad] y luego en San Vicente.

El mero día de San Juan, mientras los revoltosos estaban festejando, se oyeron disparos, eran los soldados con Pedro Castro a la cabeza que venía con refuerzos. Los revoltosos salieron huyendo. Su jefe era Celso Vega. El estaba en contra de los revoltosos. Así me lo contó el mismo Pedro Castro. Los revoltosos destruyeron y se comieron todo, mataron a varias personas, entre ellas a mi tío y un niño de once años (Benito Peralta).

Al mismo tiempo que en su mayor parte expresan un gran desconocimiento acerca de lo que eran los magonistas, la revolución mexicana y los propósitos de los revolucionarios, reconocen que el conflicto magonista involucró conflictos intershumules:

Pedro Castro es paipai del shumul miakuá que quiere decir, el que está en el cielo (Benito Peralta).

No, no, él no andaba con los revoltosos, él estaba en su casa, allí lo mataron. Entonces pa'acá [se refiere a Arroyo de León], mi papá, mi hermano y mi tío también, entraron con los revoltosos (Trini Uchurte).

Posiblemente dicho conflicto se mantenga vivo en la actualidad:

No pues si lo mataron [al tío de Benito] es porque él tuvo la culpa, él empezó a hacer cosas a los revoltosos; no ellos, sino que había un señor mexicano que él fue el que les tiró.

La gente que venían eran por abajo, como ellos vivían así les salió la infantería aquí, les disparó, en la noche fue, y le tocó al tío, al que estaba tirando se fue, mataron al viejo (Carlos Cañedo).

Benito Peralta, a la distancia de ocho décadas, a través de su contacto con investigadores y lecturas recientes ha llegado a establecer un razonamiento diferente al comunmente escuchado entre los indígenas acerca de los magonistas:

Estaban en contra de los ricos, de los millonarios y los ganaderos, porque los extranjeros tenían todo mientras que el meramente dueño andaba de allá para acá. Esto lo leí hace poco. Ricardo Flores Magón 
era un héroe, porque el pleito que hizo era por la gente pobre, por eso nunca lo mencionan en la historia.

Pero a pesar de que los magonistas estaban por los pobres, trataron mal a los indios, lo que buscaban era bueno, pero como venían de muchas razas con ellos, hicieron daño a los pobres no a los ricos (Benito Peralta).

En la tercera etapa dentro de la periodización histórica de los indígenas se encuentran la colonización de gambusinos y latifundistas, su presencia es asociada con la ambición y el despojo de los aborigenes:

Sí, una vez llegaron dos a pie aquí, eran gringos, un hombre y una mujer. Fue como en el 25 [1925] ó el 30 [1930] que sucedió esto, por "ay" más o menos, no me acuerdo. Aquí no encontraron nada y se fueron; aquí andaban con los kiliwas, venían a buscar mica y todo eso (Trini Uchurte).

Después vinieron los Loperena, españoles, pero hace poco. Sí. españoles eran, sí, ahora ya murieron ellos, los meramente, porque estos son los hijos, estos sín acieron aquí, y la madre es mexicana, pero todavía siguen ahí viviendo.

Compraron ese rancho en 1909, ya es rancho viejo, es casa que ellos compraron y compraron ese rancho. Entonces vivía la gente aquí en el volcán que le nombran. Así pues vivía la gente cuando entraron los Loperena; la gente se empezó a salir, como era gente de otra clase, no sabían hablar, y lueguito se escondían... y tuvieron que retirarse. Se fueron ahorillando poco a poco, empujando pa' fuera... (Benito Peralta).

Curiosamente, en esta última etapa, cuando los indígenas se encontraban ante un proceso avanzado de aculturación y de destrucción de su medio ambiente, la colonización de norteamericanos es asociada como benefactora:

Después de los frailes, vinieron posiblemente gringos, pero nomás a visitar, no a quitar nada. Ellos trataban con cariño a los indios, con amabilidad (Benito Peralta).

Al mismo tiempo que la presencia de los mexicanos es valorizada como negativa, así como la relación del gobierno con los indígenas, pues según afiman, gracias a sus quejas han obtenido que la indiferencia ante sus problemas, sea menor:

...bueno pues aquí nos tienen, ni nos hacían caso, y todavía; por ahora antisiquiera de reojo nos miran. Sí, aunque sea de reojo (Benito Peralta). 


\section{CONCLUSIONES}

Como podemos apreciar, la historia contada por los indígenas es una historia que no reconoce la identidad de los protagonistas, pero los identifica pragmáticamente a través de sus hechos, es una historia atemporal que no respeta tiempos históricos y mucho menos fechas, pero que se vertebra a partir de momentos perfectamente definidos, que ignora interpretaciones pero que resume acciones y resultados; en fin, es un discurso ahistórico que puede auxiliar en la lectura de la historia de estos grupos étnicos.

En primer lugar, para los indígenas el mundo está dividido entre nosotros y ustedes; $y$ no es que no reconozcan las especificidades culturales de los distintos grupos con los que interactúan, sino porque la dinámica histórica de relación entre indígenas y no indígenas se ha definido siempre por una serie de prácticas negativas por parte de estos últimos, que van desde la expoliación, el engaño, el maltrato y el abuso sexual sobre las distintas tribus sin distinción alguna, generando el fortalecimiento de una identidad pluriétnica que antiguamente no tenían como consecuencia de su vida nómada y de su organización en linajes; cuestión que les ha permitido asumir conscientemente que su marginalidad es producto de una acción de quienes no son como ellos.

Por esta razón, los indígenas han asumido pragmáticamente la identificacion de "los otros", como aquellos que venían por tierras o por oro, porque les legaron un idioma y una religion, porque les robaban a sus mujeres o a sus tesoros más sagrados, porque construían ostentosas maravillas, porque los masacraron, etcétera.

$\mathrm{La}$ anterior interpretacion la hacen traspolando procesos históricos recurriendo constantemente al absurdo, que no deja menos que confirmar nuestras dos conclusiones anteriores; los misioneros venían por tierra y por oro en un momento en que no existía aún el deslinde territorial ni el hallazgo de vetas aurfferas importantes; los magonistas eran simultáneamente revoltosos y de la acordada, algo menos que judiciales - afirman-, porque alteraron su tranquilidad con atropellos salvajes; y finalmente, los mineros fueron a sacar tesoros arqueologicos del cementerio.

Así, resumen cada uno de los momentos históricos que identifican, y que son parte de todo un proceso de colonización que ha tomado siglos, y que ha venido a culminar en acciones institucionales sobre sus comunidades que igualmente han sido de carácter colonizador, acciones asistencialistas que no han encontrado mejor definición que la de Don Benito Peralta, “...pos ahora antisiquiera de reojo nos miran”. 


\section{BIBLIOGRAFÍA}

ASCHMANN, Hommer. 1965. "Historical Sources for a Contact Ethnography of Baja California", Historial Society Quaterly, vol. 44, núm. 2; San Francisco, California.

LEON, Miguel Portilla. 1983. "Los Primeros Californios; Prehistoria y Etnohistoria", Panorama Histórico de Baja California, Capítulo II, Centro de Investigaciones Históricas, UNAM-UABC, Tijuana, Baja California.

MIXCO, Mauricio. 1983. "Etnohistoria Pai-pai en Baja California", Meyibo, núm. 4, Centro de Investigaciones Históricas, UNAMUABC, Tijuana, Baja California.

OWEN, Roger. 1963. "Indians and Revolution: the 1911 Invasion of Baja California, Mexico", Etnohistory, vol.10, núm. 4; American Etnohistoric Conference; Bloomington, Indiana. 